\title{
Poland anomaly with contralateral ulnar ray defect
}

\author{
C V E Powell, R C Coombs, T J David
}

\begin{abstract}
We report an atypical case of the Poland anomaly. Unreported features are that the hand abnormality is on the contralateral side to the chest wall defect, there is an ulnar ray predominance, and lack of syndactyly.

(F Med Genet 1993;30:423-4)
\end{abstract}

The Poland anomaly comprises unilateral absence of the pectoralis major muscle with an ipsilateral hand defect. ${ }^{1-8}$ We report a patient with atypical and previously unreported features.

\section{Department of \\ Paediatrics, Sheffield \\ Children's Hospital, \\ Sheffield S10 2TH, \\ UK. \\ C V E Powell}

\section{Department of Neonatology, Northern General Hospital, Herries Road, Sheffield S5 7AU, UK. \\ R C Coombs}

Department of Child

Health and

Paediatrics,

University

Department of Child

Health, Booth Hall

Children's Hospital,

Manchester M9 2AA,

UK.

T J David

Correspondence to Dr Powell,

46 Millhouses Lane,

Sheffield S7 2HB.

Received 26 August 1992. Accepted 10 September 1992

\section{Case report}

The proband was the first child of healthy, non-consanguineous parents (father aged 27 years, mother aged 26 years). There was no family history of congenital malformations. Pregnancy was normal until the onset of preeclampsia at 32 weeks' gestation. The mother had not been taking oral contraceptives and there was no other history of maternal drug ingestion in pregnancy. Delivery was at 35 weeks' gestation by normal vaginal delivery, birth weight $2370 \mathrm{~g}$ (25th centile). Nasal continuous positive airway pressure was required for respiratory distress syndrome for $\mathbf{4 8}$ hours, but thereafter his progress was uneventful.

His abnormalities comprised a right sided chest wall defect and a left sided upper limb defect. There was absence of the sternocostal head of the right pectoralis major muscle, with a normal clavicular head and no axillary web (fig 1). The anterior portions of the right third

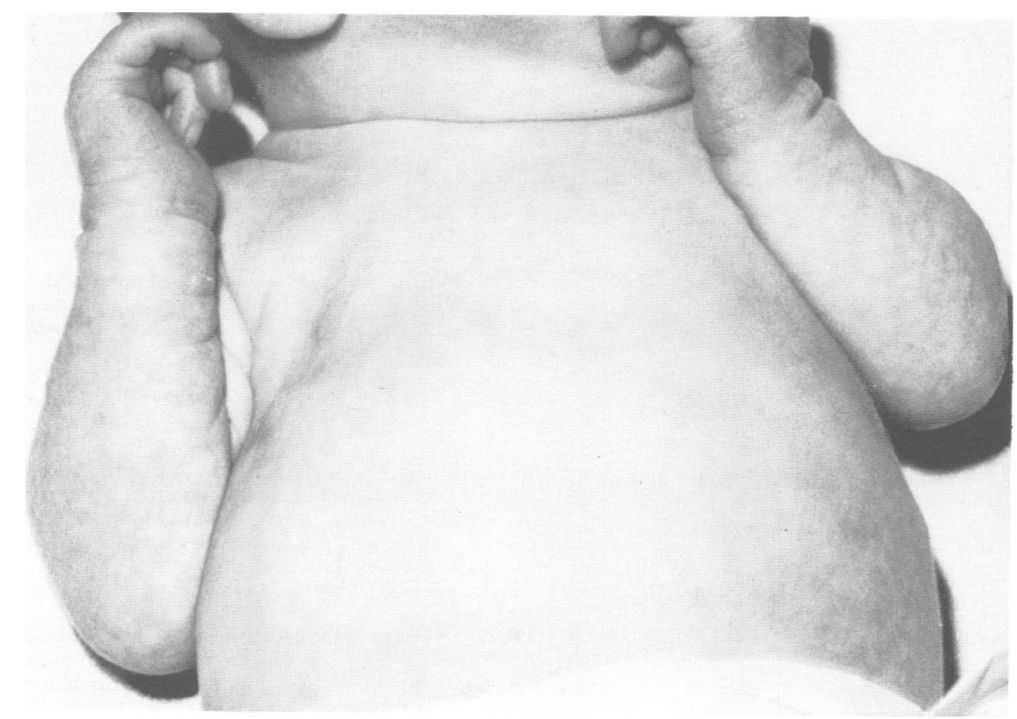

Figure 1 A right sided chest wall deformity with absence of the sternocostal head of the pectoralis major muscle. and fourth ribs were impalpable, associated with a depression of the chest wall in this area and paradoxical movement of the chest wall with respiration. The nipples were normal and there was no winging of the scapulae. The right hand was normal. The left arm was hypoplastic and shortened, especially the forearm. The left thumb and index finger were normal but the left middle finger was hypoplastic. The left little and ring fingers were absent (fig 2). At the age of 5 months, he is asymptomatic, growing and developing normally, and he has no detectable cranial nerve abnormalities.

Radiographs taken at the age of 2 days showed absence of the anterior ends of the third and fourth ribs on the right side and a hypoplastic left radius and ulna as well as absence of the left ring and little fingers.

\section{Discussion}

The clinical features of the Poland anomaly are variable in severity ${ }^{7}$ and in some cases the chest wall defect is not accompanied by any limb abnormality. ${ }^{4} 7$ The limb deformity typically comprises shortening of the fingers with cutaneous syndactyly of the index and middle fingers. ${ }^{47}$ In more severe cases, the fingers are all markedly shortened and webbed. Occasionally the index, middle, and ring fingers are completely absent with preservation of the little finger and the thumb. ${ }^{57}$

The atypical features in this case are the lack of syndactyly, the ulnar predominance, and the contralateral side of the limb defect. These features represent an extension of the previously recognised spectrum of the Poland anomaly.

There is a recognised association between the Möbius syndrome and the Poland anomaly. ${ }^{2}$ This is relevant to the present case because the Möbius syndrome has been reported in a child with an absent pectoralis major muscle on the right side and hypoplasia and syndactyly of the fingers on the left hand. ${ }^{9}$ The patient also had absent fingers on the right hand with a hypoplastic thumb. The case reported here had no features of the Möbius syndrome.

The aetiology of the Poland anomaly is uncertain. Bouvet et al,,$^{5}$ using plethysmography, showed a significant decrease of the velocity of the systolic increase in the arterial volume in affected arms of eight children with the Poland anomaly compared to eight control children with normal limbs. It was suggested that hypoplasia of the ipsilateral subclavian artery was the origin of the malformation.

Bouwes Bavinick and Weaver ${ }^{10}$ have 


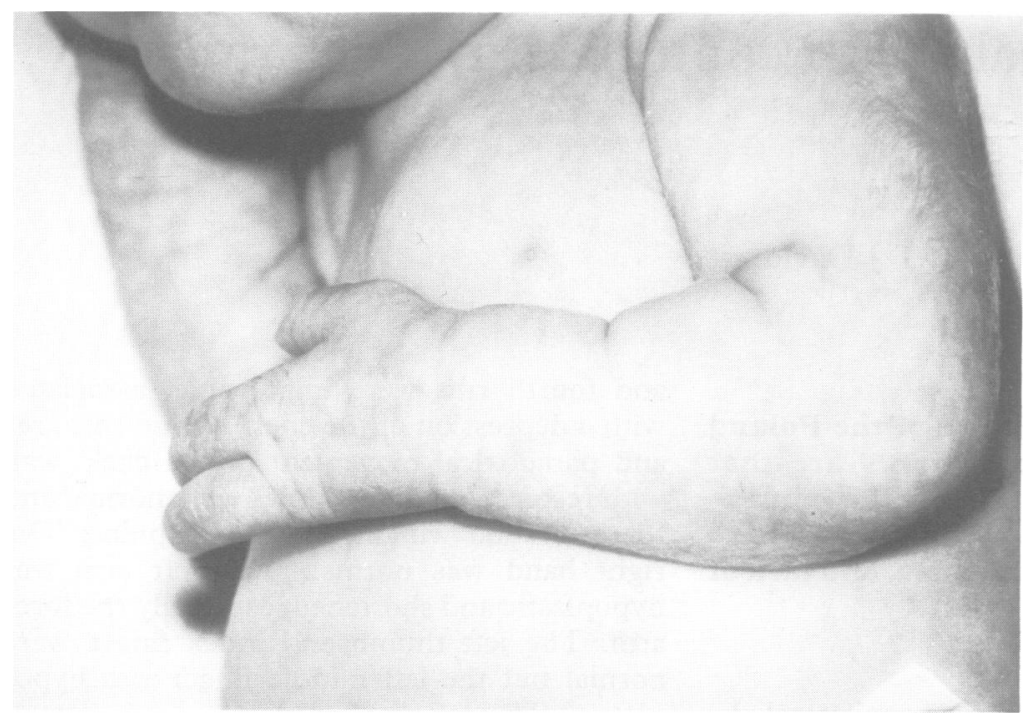

Figure $2 A$ left-sided hand abnormality with absent little and ring fingers, hypoplastic middle finger, and normal thumb.

suggested the term 'subclavian artery supply disruption sequence' (SASDS) to explain a common pathogenesis in Poland, Klippel-Feil, and Möbius syndromes, isolated terminal transverse limb defects, and the Sprengel anomaly. They propose that interruption of the early embryonic blood supply in the subcla- vian arteries or vertebral arteries at about 6 weeks' gestation may produce predictable patterns of defects depending on where the restriction of blood flow occurs. However, a case such as the present one, in which the contralateral arm is affected, is not consistent with a vascular theory. It seems more probable that any hypoplasia of the subclavian artery is merely one feature of the upper limb hypoplasia, and there is no evidence for a causal relationship.

1 Poland A. Deficiency of the pectoral muscles. Guys Hosp Rep 1841;6:191-3.

2 Beals RK, Crawford S. Congenital absence of the pectoral muscles: a review of twenty-five patients. Clin Orthop 1976;119:166-71.

3 Ireland DC, Takayama N, Flatt AE. Poland's syndrome: a review of forty three cases. $\mathcal{f}$ Bone foint Surg $(\mathrm{Am})$ 1976;58:52-8.

4 Castilla EE, Paz JE, Orioli M. Pectoralis major muscle defect and Poland complex. Am f Med Genet 1979;4:263

5 Bouvet JP, Leveque D, Bernetieres F, Gros JJ. Vascular origin of Poland syndrome? Eur $\mathcal{F}$ Pediatr 1978;128:1726.

6 Gausewitz SH, Meals RA, Setoguchi Y Severe limb deficiency in Poland's syndrome. Clin Orthop 1984;185:9-13. David TJ. The Poland anomaly. MD thesis, University of Bristol, 1981.

8 David TJ, Winter RM. Familial absence of the pectoralis major, serratus anterior, and latissimus dorsi muscles. $\mathcal{F}$ Med Genet 1985;22:390-2.

9 Jorgenson RJ. Möbius syndrome, ectrodactyly, hypoplasia of the tongue and pectoralis muscles. Birth Defects 1971;7:283-4.

10 Bouwes Bavinck JN, Weaver DD. Subclavian artery supply disruption sequence: hypothesis of a vascular etiology for Poland, Klippel-Feil and Möbius anomalies. $A m \mathcal{f} M e d$ Genet 1986;23:903-18. 